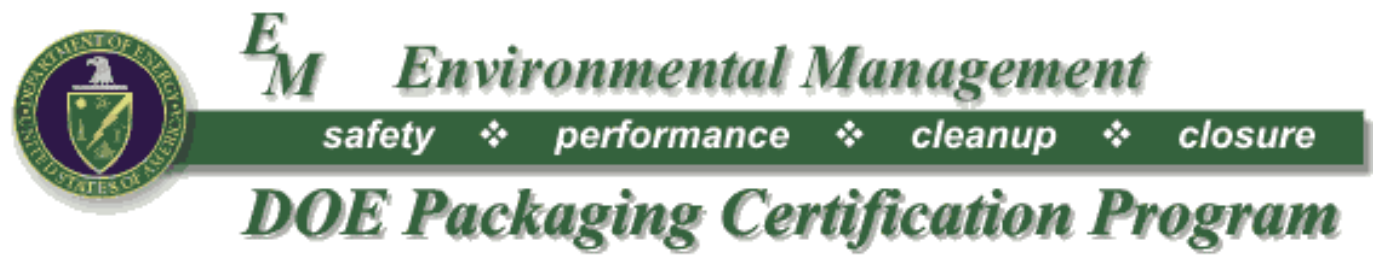

Keywords: Package, RF, Magnetic Field, Wireless

Communication

Retention: Permanent

\title{
9977 Type B Packaging Internal Data Collection Feasibility Testing - Magnetic Field Communications
}

May 2012

Savannah River National Laboratory Savannah River Nuclear Solutions, LLC Aiken, SC 29808

Prepared for the U.S. Department of Energy under

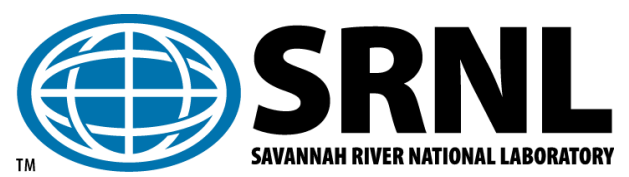
contract number DE-AC09-08SR22470. 
L-TSM-A-00003

Revision 0

\section{DISCLAIMER}

This work was prepared under an agreement with and funded by the U.S. Government. Neither the U.S. Government or its employees, nor any of its contractors, subcontractors or their employees, makes any express or implied:

1. warranty or assumes any legal liability for the accuracy, completeness, or for the use or results of such use of any information, product, or process disclosed; or

2. representation that such use or results of such use would not infringe privately owned rights; or

3. endorsement or recommendation of any specifically identified commercial product, process, or service.

Any views and opinions of authors expressed in this work do not necessarily state or reflect those of the United States Government, or its contractors, or subcontractors.

\section{Printed in the United States of America}

Prepared for

U.S. Department of Energy 


\section{REVIEWS AND APPROVALS}

AUTHOR:

Signature on File

$6 / 8 / 2012$

Davis J. Shull, Instrumentation and Electronics Development

Date

TECHNICAL REVIEW:

Signature on File

$6 / 8 / 2012$

Joseph V. Cordaro, Research and Development Engineering Date

Signature on File

$6 / 8 / 2012$

Lawrence F. Gelder,

Date

Packaging Technology and Pressurized Systems

APPROVAL:

Signature on File

$6 / 8 / 2012$

George E. Weeks, Manager

Date

Instrumentation and Electronics Development

Signature on File

$6 / 18 / 2012$

Jeffery L. England, EM-33 Program Manager

Date

Packaging Technology and Pressurized Systems

Approved by Email

$6 / 15 / 2012$

Dr. James M Shuler, Manager

Date

DOE Packaging Certification Program, EM-33 


\section{EXECUTIVE SUMMARY}

The objective of this report is to document the findings from proof-of-concept testing performed by the Savannah River National Laboratory (SRNL) R\&D Engineering and Visible Assets, Inc. for the DOE Packaging Certification Program (PCP) to determine if RuBee (IEEE 1902.1) tags and readers could be used to provide a communication link from within a drum-style DOE certified Type B radioactive materials packaging. A Model 9977 Type B Packaging was used to test the read/write capability and range performance of a RuBee tag and reader. Testing was performed with the RuBee tags placed in various locations inside the packaging including inside the drum on the outside of the lid of the containment vessel and also inside of the containment vessel. This report documents the test methods and results. A path forward will also be recommended. 


\section{TABLE OF CONTENTS}

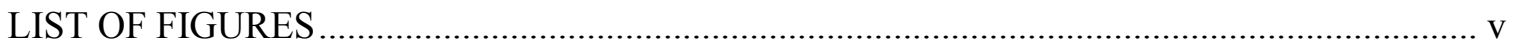

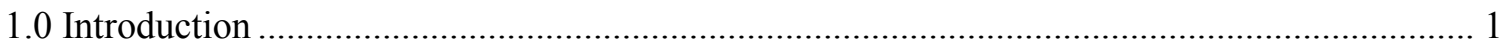

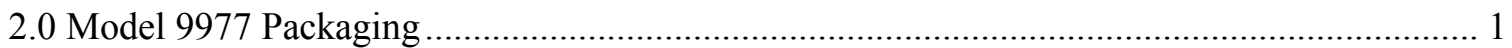

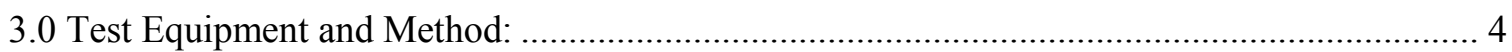

3.1 Visible Assets RuBee Hardware and Other Test Equipment Used ................................... 4

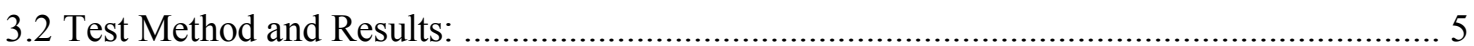

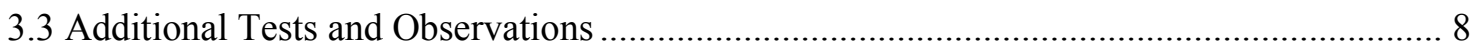

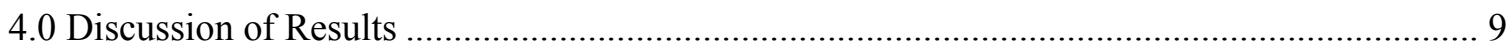

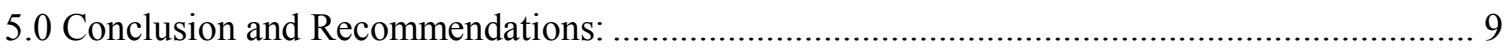




\section{LIST OF FIGURES}

Figure 2-1. Model 9977 Type B package cross section. ............................................................ 2

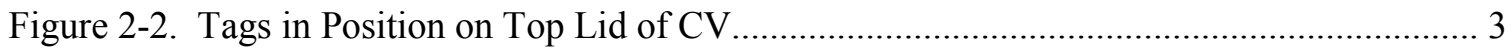

Figure 2-3. Tags Secured to Underside of CV Lid ................................................................... 3

Figure 2-4. Single Tag Placed Inside of CV on Sidewall ........................................................... 4

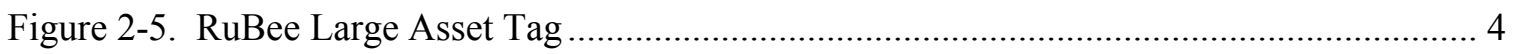

Figure 3-1. Baseline Measurement Setup................................................................................ 5

Figure 3-2. Baseline Signal Strength vs. Distance with Tags on Outside Drum Lid .................... 5

Figure 3-3. 9977 Test Configuration with Tags on Outside Top of CV Lid ................................. 6

Figure 3-4. Signal Strength vs. Distance with Tags on Outside Top of CV Lid ........................... 6

Figure 3-5. Existing Hole in CV Bottom Plugged for Test ...................................................... 7

Figure 3-6. Example of Hardware Used to Plug Hole in CV …................................................. 7

Figure 3-7. Two-way Communication with Tags on Inside of CV Attached to Lid..................... 8

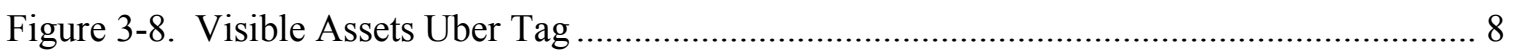




\section{LIST OF ABBREVIATIONS}

$\begin{array}{ll}\text { AES } & \text { Advanced Encryption Standard } \\ \text { AP } & \text { Access Point } \\ \text { CV } & \text { Containment Vessel } \\ \text { EMI } & \text { Electromagnetic Interference } \\ \text { EMC } & \text { Electromagnetic Compatibility } \\ \text { IEEE } & \text { Institute of Electrical and Electronics Engineers } \\ \text { PCP } & \text { DOE Packaging Certification Program } \\ \text { SRNL } & \text { Savannah River National Laboratory }\end{array}$




\subsection{Introduction}

The objective of this report is to document the results of proof-of-concept testing performed to determine if magnetic field communications could be used as a means of sensor communication from within a stainless steel drum-style DOE certified Type B radioactive materials packaging. These tests were performed using Visible Assets, Inc. RuBee (IEEE 1902.1) tags and reader (basestation and antenna) with a Model 9977 radioactive materials packaging. The Model 9977 is representative of similar DOE certified drum style packagings such as the 9978 and 9975 models. This report will document the test methods and results and provide recommendations for a path forward.

RuBee is a peer-to-peer packet based communication protocol that operates at a frequency of 131 $\mathrm{kHz}$. In this frequency range, $99.999 \%$ of the energy is magnetic when operating in the near field of the radiating antenna. At $131 \mathrm{kHz}, \mathrm{RuBee}$ signals have a wavelength of approximately 2,289 meters or about 1.25 miles. The near field region is considered to be the range up to $1 / 10^{\text {th }}$ of a wavelength from the source. So for RuBee, near field properties dominate at distances up to 229 meters or about $1 / 8^{\text {th }}$ of a mile. Most RuBee applications involve tag to reader antenna distances of 10 to 20 feet; however, tag ranges of up to 50 feet or more are achievable depending on tag and antenna design and propagation losses. In terms of antenna voltage measured, RuBee signal strength also diminishes more rapidly with distance than radio frequency (RF) waves, falling off at a rate of $1 / R^{3}$ versus $1 / R$ for $R F$ (where $R$ is range from the source). This feature greatly reduces the risk of eavesdropping and mitigates unintentional, compromising emissions and emanations. As a magnetic field wave, RuBee is also not as susceptible as higher frequency radio waves to the negative effects of metal and liquids. RuBee tags have memory, a crystal for tracking time, and utilize Advanced Encryption Standard (AES) encryption for data security. Because of its low frequency/long wavelength and low power characteristics, RuBee is an attractive technology for applications that require high security, human safety, intrinsic safety, low EMI and EMC, long battery life, operation in harsh places, and operation near or on steel and liquids. For a shipping and storage package application, RuBee tags can be integrated with sensors for monitoring temperature, vibration, shock, humidity, and other diagnostics. The expected battery life for RuBee is $15-25$ years.

\subsection{Model 9977 Packaging}

The cross section of the Model 9977 packaging is shown in Figure 2-1. In the case of a sealed package, layers of stainless steel and polyurethane foam insulation will attenuate any direct signal propagating from the interior of the drum to an external antenna and reader. For the 9977 the drum lid is held in place by eight, 5/8-inch flange bolts and washers, which are torqued to a value of $45( \pm 5) \mathrm{ft}-\mathrm{lbs}$. The lid to drum closure interface is stainless-on-stainless contact surface seal, without a gasket and is not intended to be airtight.

For the testing described in this document, RuBee tags were placed in two locations as indicated by the red stars in Figure 2-1. Tests were performed with the drum lid flange bolts initially hand tight, and then repeated with the bolts torqued to the required specification. For the first test, two large asset RuBee tags were placed on the outside of the containment vessel (CV) lid and secured by tape (See Figure 2-2). The aluminum top load distribution fixture was removed for this test to provide the vertical clearance needed to insert the outer two RuBee tags in the assembled packaging. In a second test, the two RuBee large asset tags were placed inside of the CV and taped to the underside of the CV lid as shown in Figure 2-3. The CV lid was then hand-tightened. In both tests, the two tags were oriented so that their internal antennas were orthogonal to each other in order to provide the best possibility of communication regardless of the orientation of the 
9977 packing. Communications with the RuBee tags are distinguished according to the Tag ID numbers. For these tests, the two orthogonal tags were assigned the same Tag ID.

Additional tests were conducted with a single RuBee large asset tag placed inside of the CV taped to the side wall (See Figure 2-4). Also, an Uber model tag with enhanced power and antenna characteristics was tested on the outside of the CV lid.

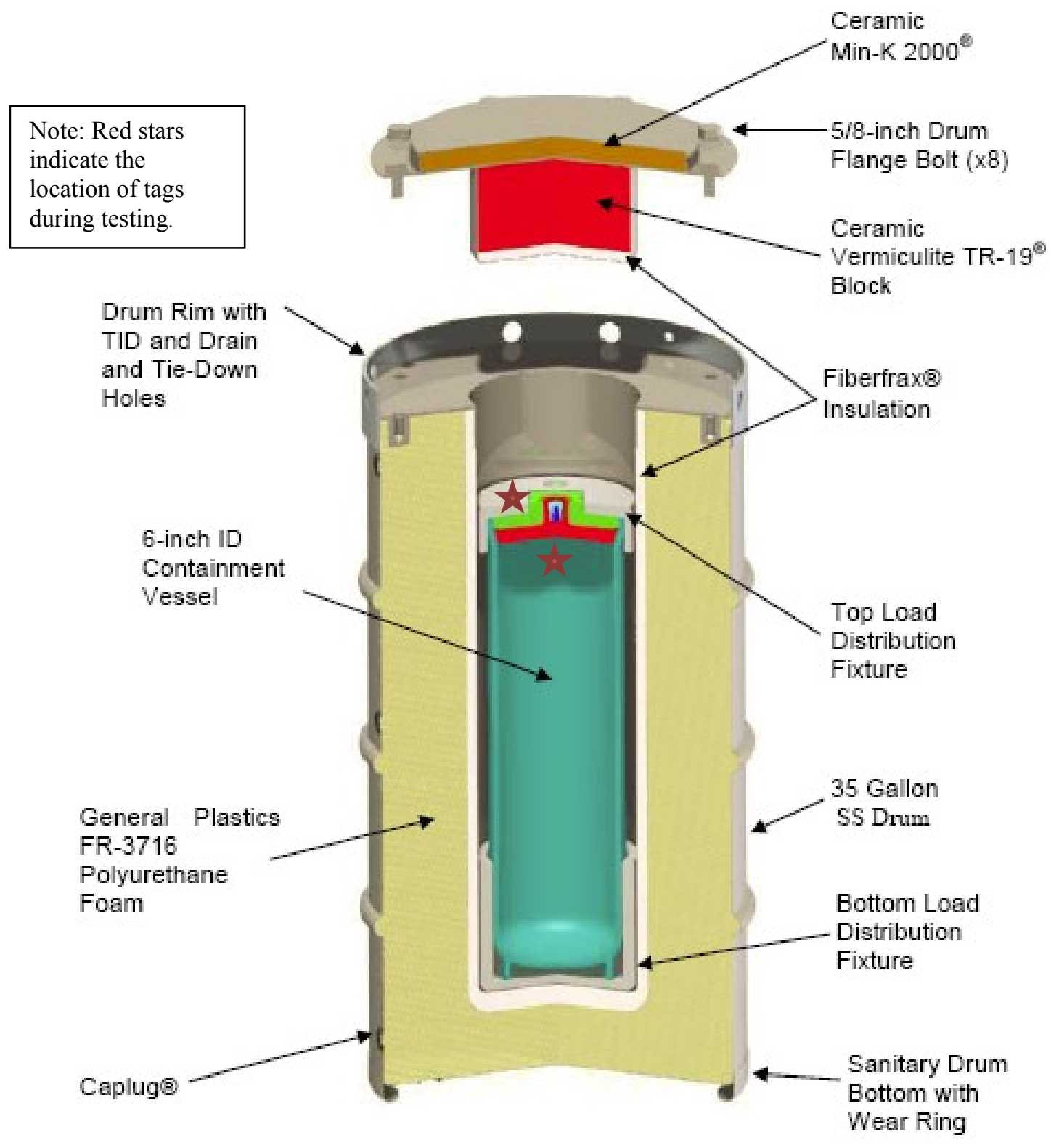

Figure 2-1. Model 9977 Packaging cross section. 


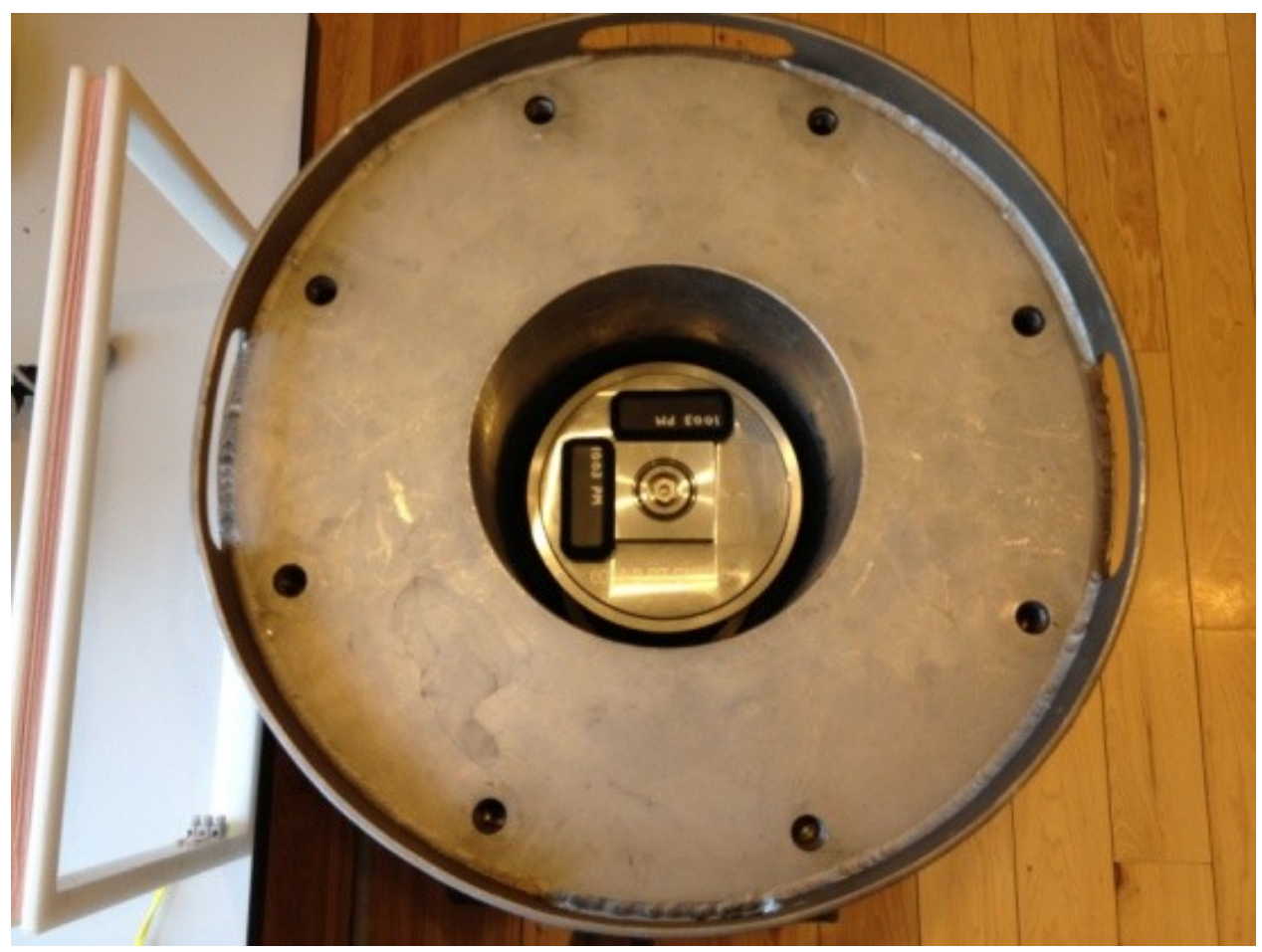

Figure 2-2. Tags in Position on the CV Lid.

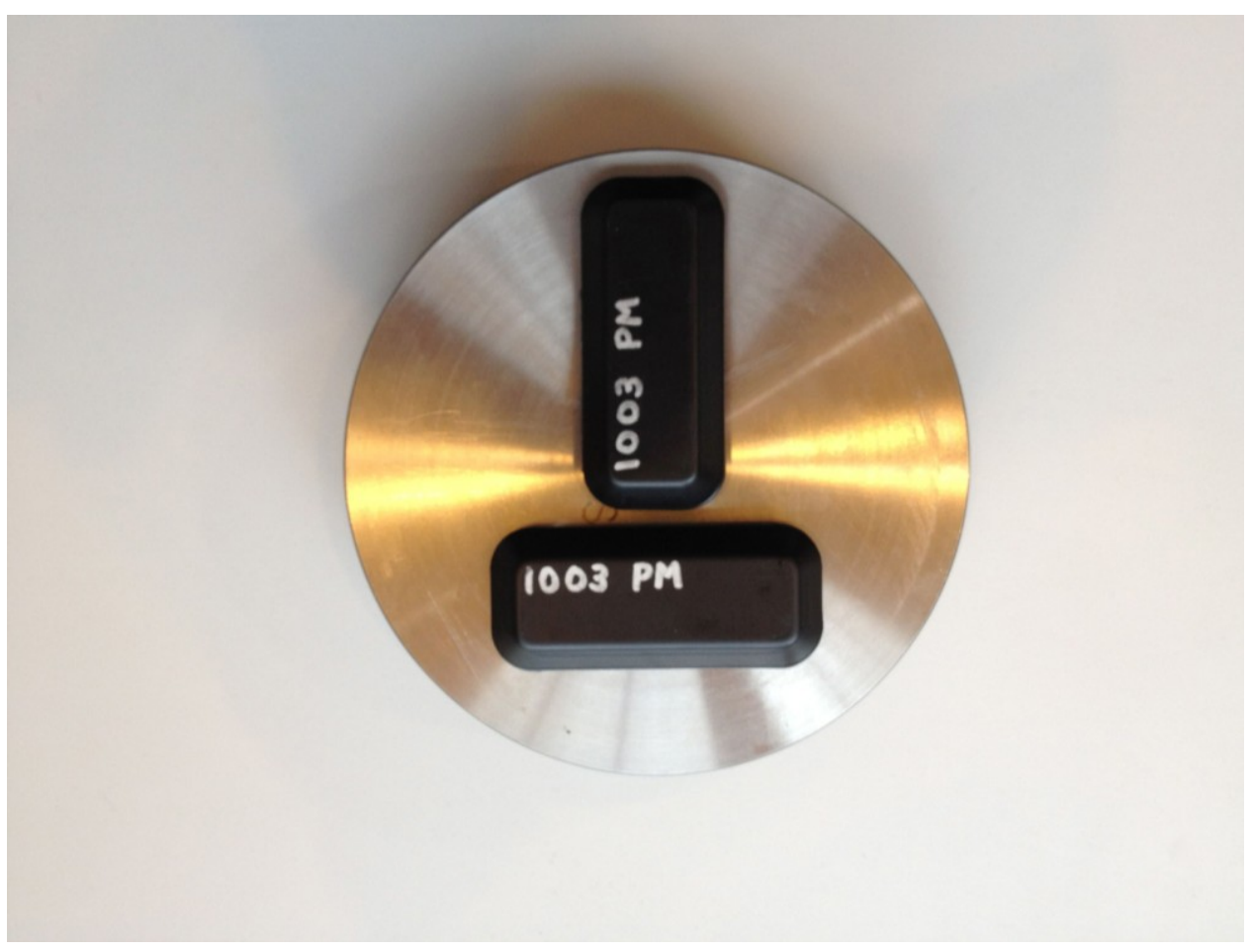

Figure 2-3. Tags Secured to Underside of CV Lid 


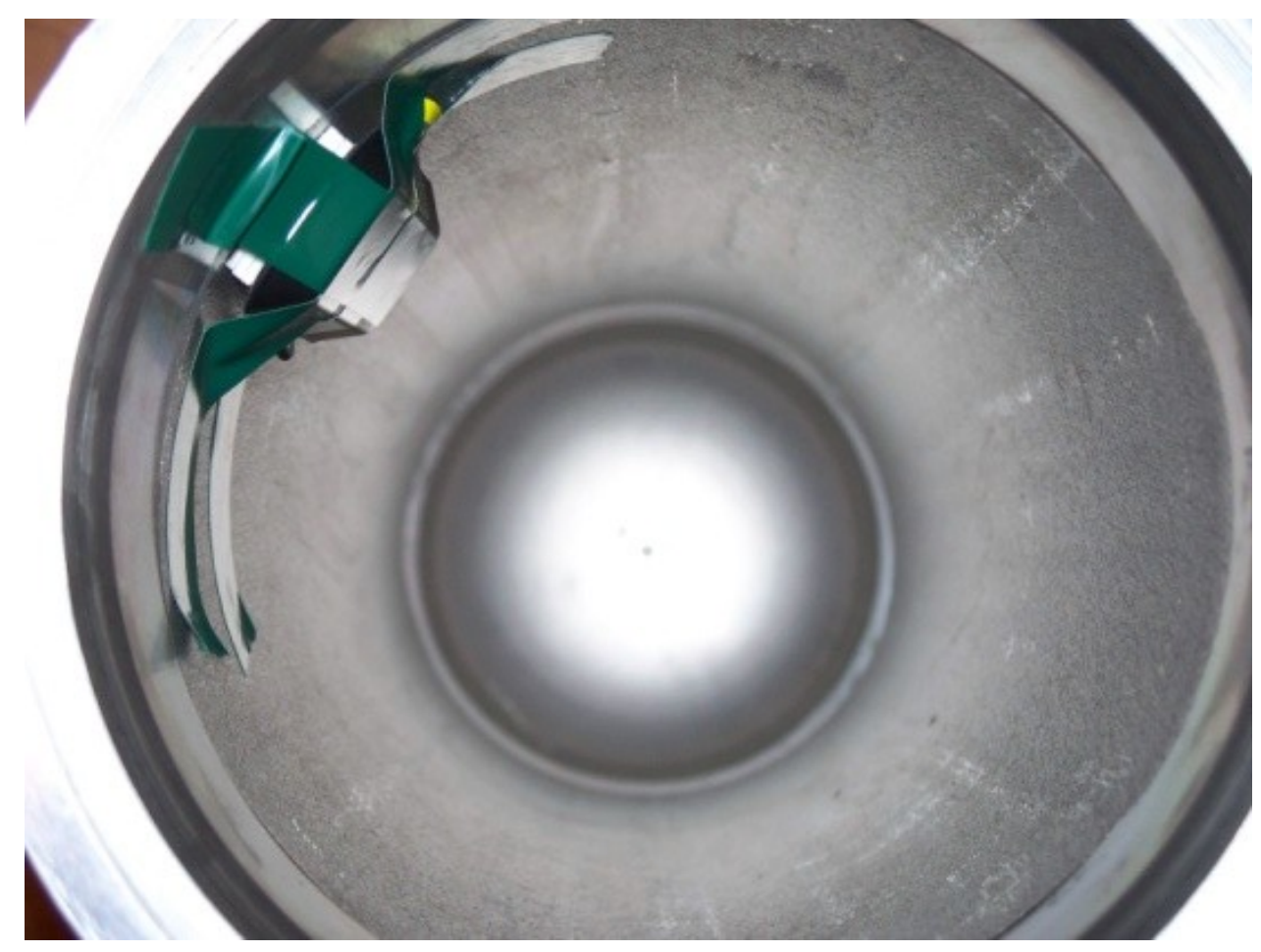

Figure 2-4. Single Tag Placed Inside the CV on the Sidewall

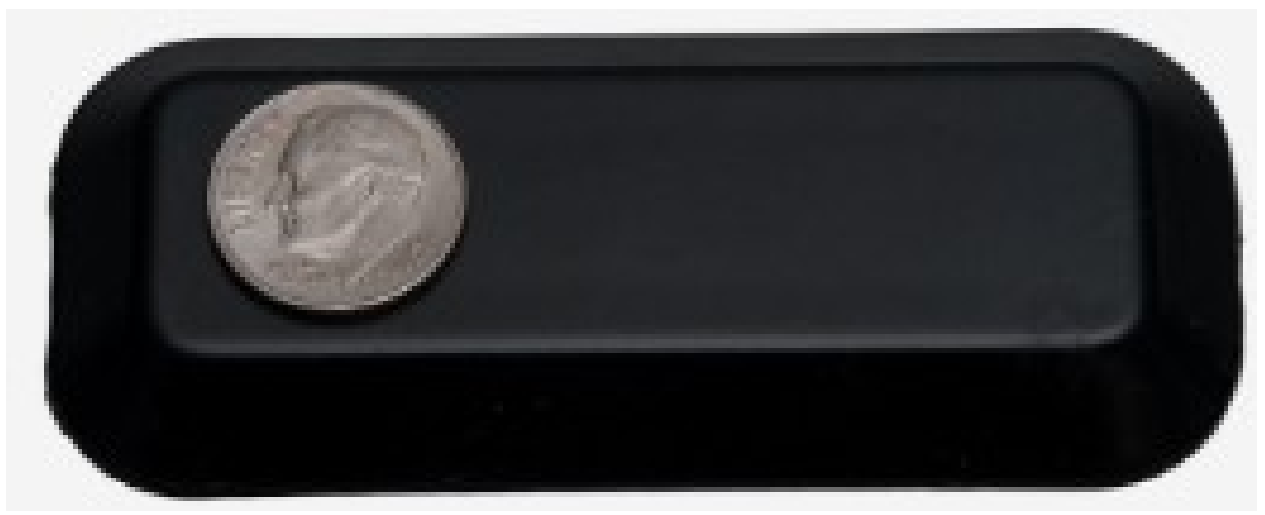

Figure 2-5. RuBee Large Asset Tag

\subsection{Test Equipment and Method:}

3.1 Visible Assets RuBee Hardware and Other Test Equipment Used

- 2 Large Asset Tags (firmware version 21)

- 1 Ranger Antenna

- 1 Version 420 BaseStation (at max transmission power setting)

- 1 Dimetix Laser Distance Sensor

- Finder Diagnostic software 


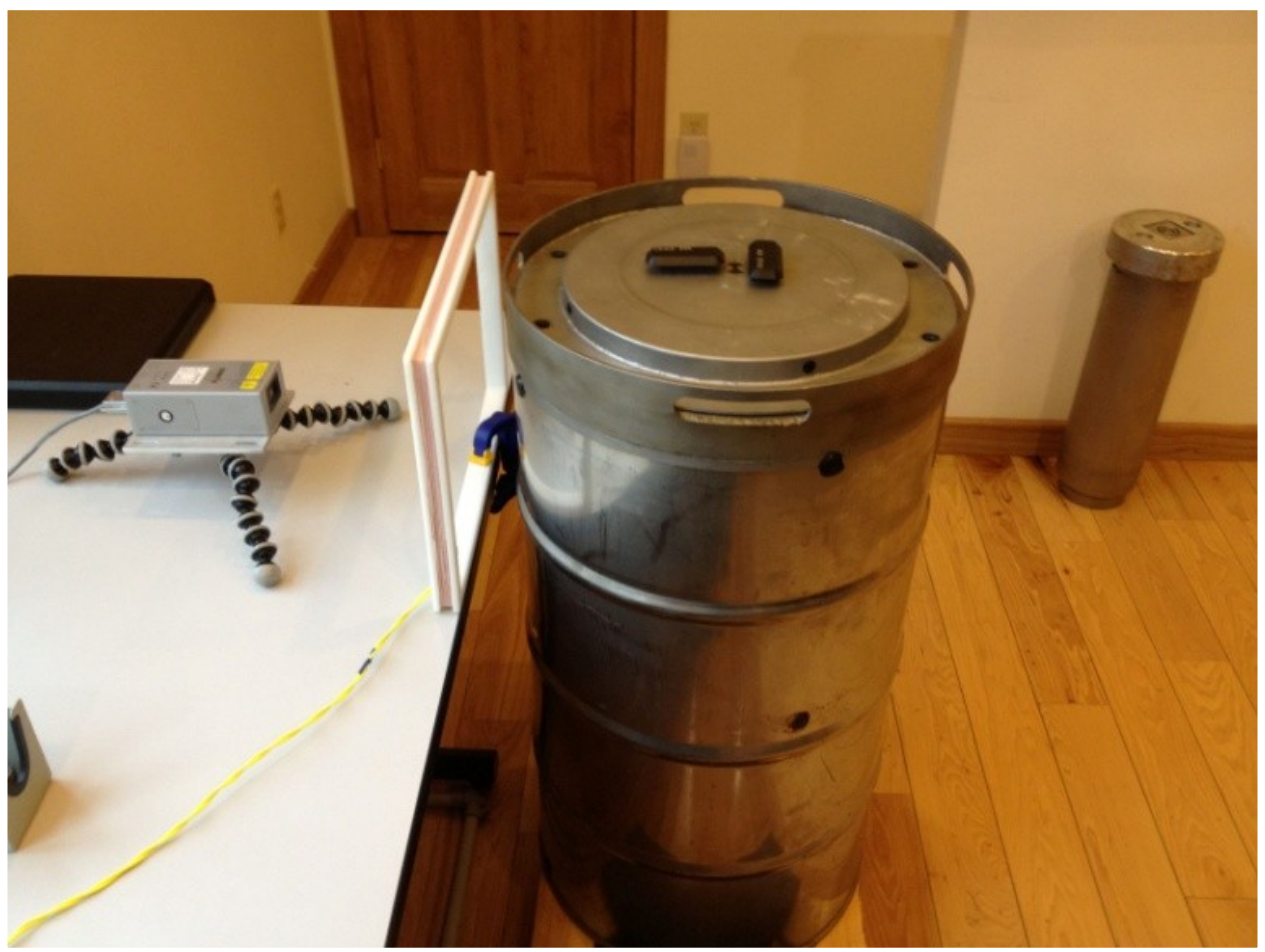

Figure 3-1. Baseline Measurement Setup.

\subsection{Test Method and Results:}

A baseline range measurement was first conducted with a pair of orthogonal tags placed on top of the drum lid (See Figure 3-1). The Finder diagnostic software first requires that the operator perform an auto-tune of the RuBee Ranger antenna. The tag ID is loaded into the software, and then the system can begin to communicate with the tag. The 9977 was placed on a 4 wheel wooden furniture dolly and then slowly moved away from the ranger antenna. The Dimetix laser distance sensor was used to measure the distance to the nearest surface of the 9977 while the tag received signal strength was recorded. The baseline plot of tag signal amplitude versus distance is shown in Figure 3-2. A successful two-way data packet communication is indicated by a green dot on the plot. A red dot indicates an unsuccessful two-way communication. The signal amplitude is given in terms of arbitrary signal units and is plotted on a linear scale. As a figure of merit, a high noise background for a RuBee system would be 100 signal amplitude units. An approximate value for the measured magnetic field strength in milli-Gauss can be obtained by dividing the signal amplitude by 100 . The maximum range achieved in this baseline test was 21.59 feet.

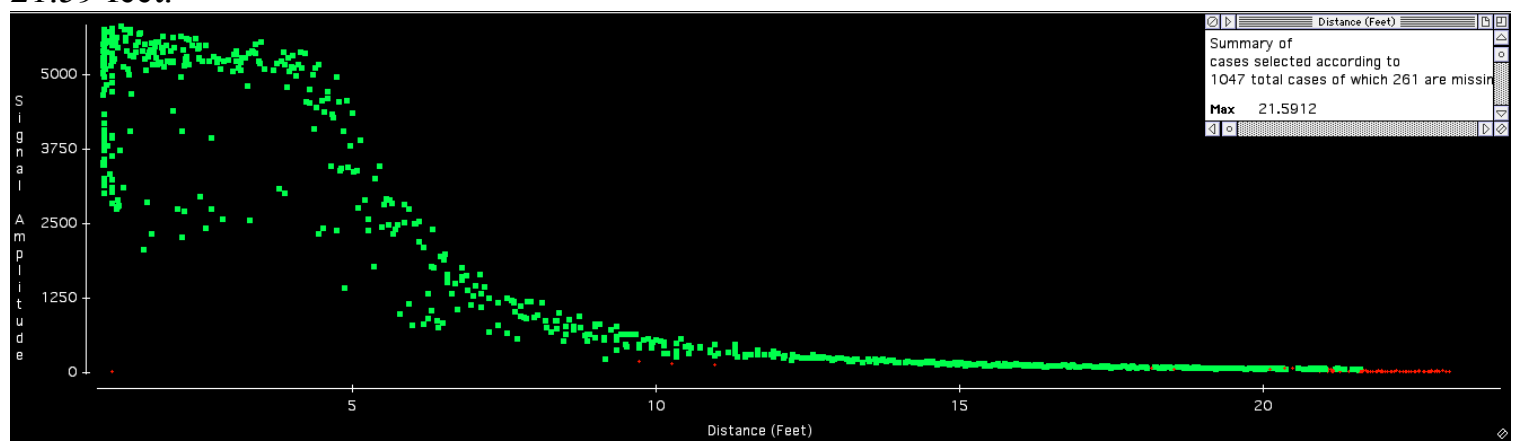

Figure 3-2. Baseline Signal Strength vs. Distance with Tags on Outside Drum Lid 
Next, the RuBee tags were placed inside of the drum on top of the CV lid as shown in Figure 2-2 and the range test was repeated. For this test, the drum lid flange bolts were only hand tight and the aluminum top load distribution fixture was removed (See Figure 3-3). The results are shown in Figure 3-4. The maximum range achieved was 4.61 feet.

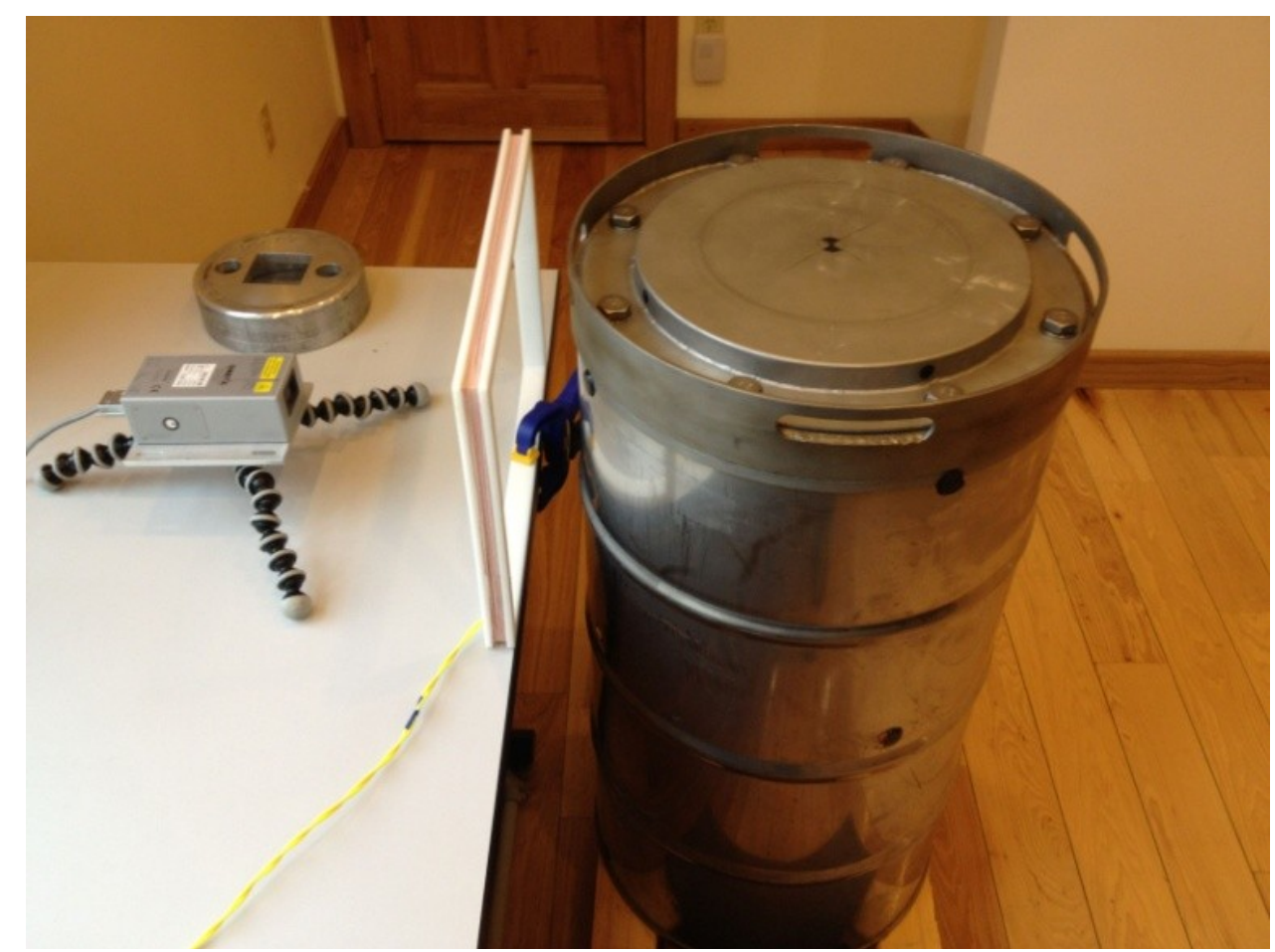

Figure 3-3. 9977 Test Configuration with Tags on Top of CV Lid

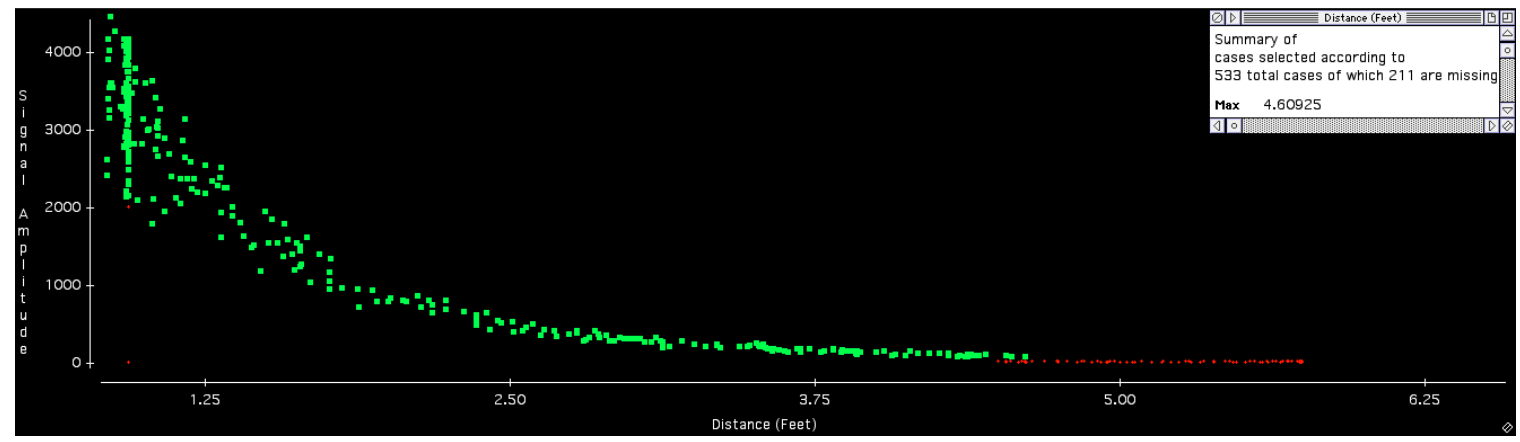

Figure 3-4. Signal Strength vs. Distance with Tags on Outside Top of CV Lid

The RuBee tags were then relocated to the inside of the CV and taped to the underside of the CV lid in the configuration shown in Figure 2-3. The CV used for this test had been previously modified with a through-wall hole located in the bottom of the CV. This hole was plugged using a metal bolt, nut and washers as shown in Figure 3-5 and Figure 3-6. The top load distribution fixture was installed for this test. The CV lid and drum lid flange bolts were hand tight. To achieve consistent two-way communication with the tags in this configuration, the Ranger reader antenna was placed in contact with the outside of the drum. Successful communication results for this arrangement are shown in Figure 3-7. The signal amplitude received in this configuration is 
approximately a factor of 3 above what would be considered a high noise background for a RuBee system.

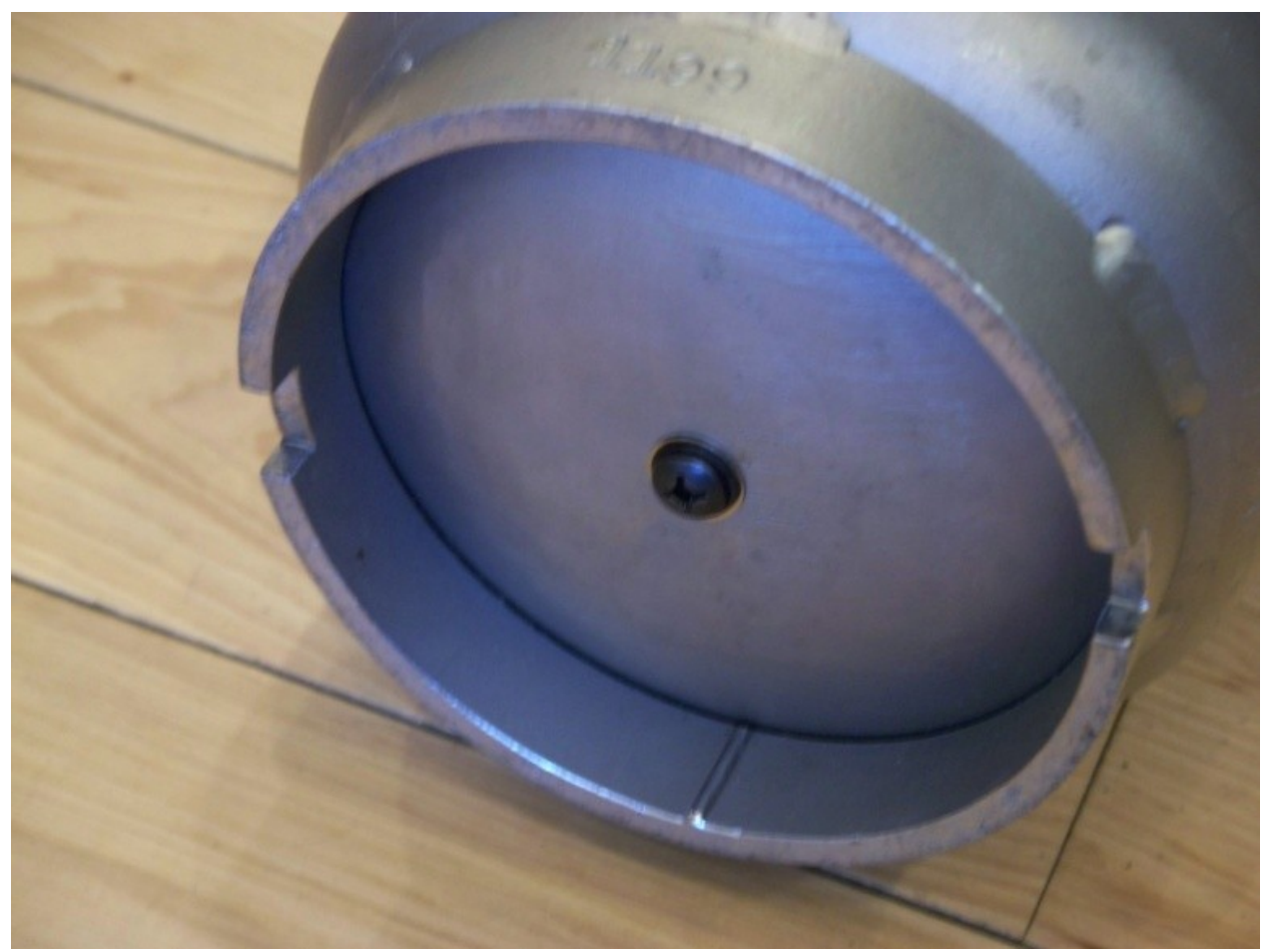

Figure 3-5. Existing Hole in CV Bottom Plugged for Test

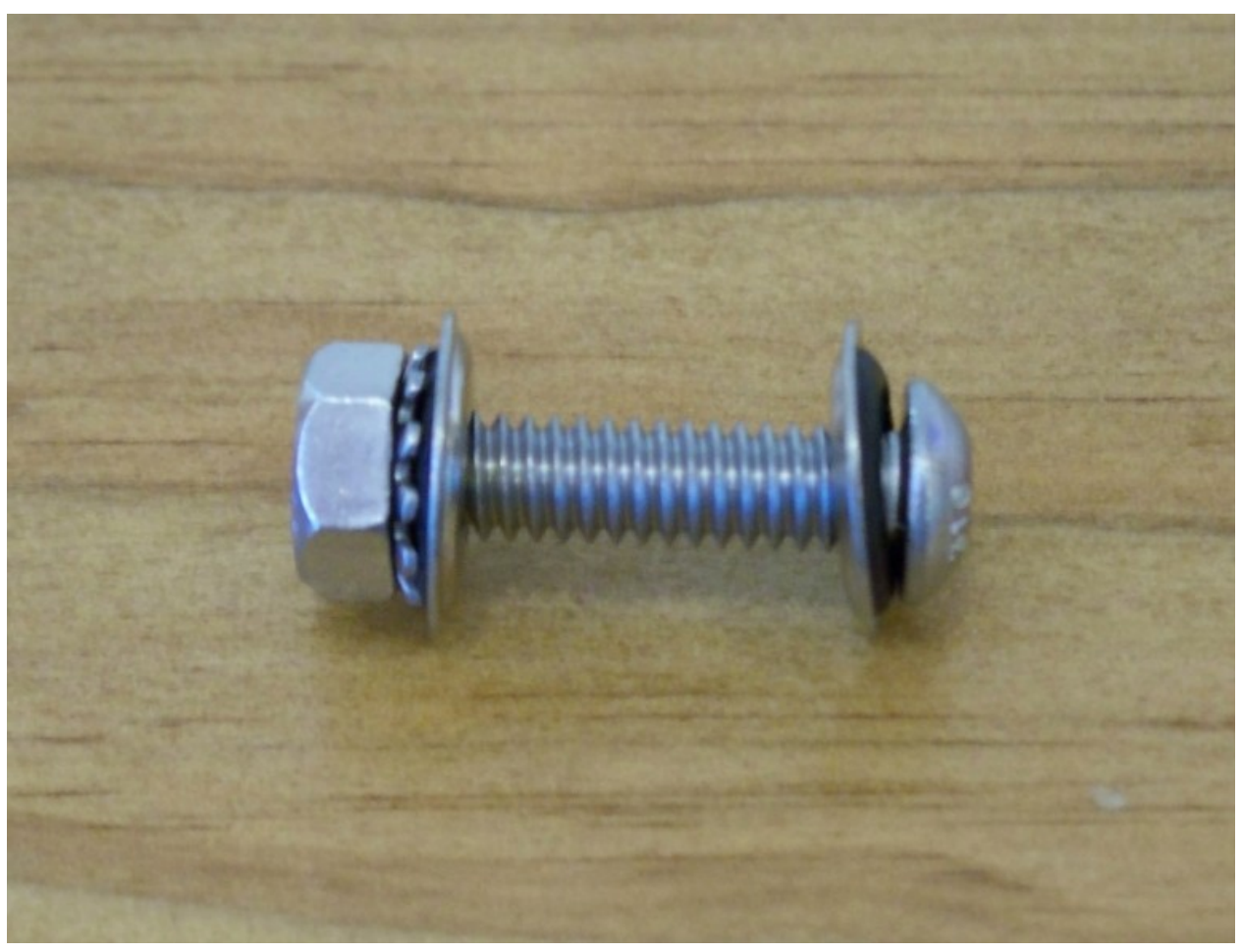

Figure 3-6. Example of Hardware Used to Plug Hole in CV 


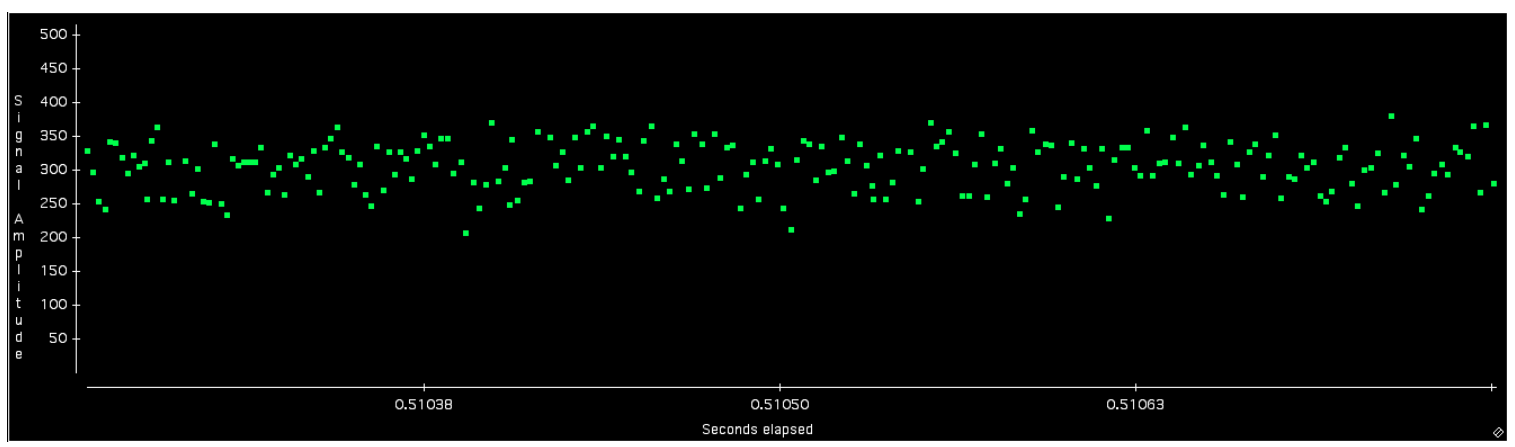

Figure 3-7. Two-way Communication with Tags on Inside of CV Attached to Lid

\subsection{Additional Tests and Observations}

The previous tests were all performed with the drum lid flange bolts only hand tight. When these tests were repeated with the bolts torqued to the specified value of $45( \pm 5) \mathrm{ft}-\mathrm{lbs}$, the communication range with the large asset tags was reduced by roughly 40 percent of the previous results. Communication with the tags placed inside the $\mathrm{CV}$ was still successful, however, with the flange bolts torqued per specification. Some improvement in detection range was observed with a single large asset tag secured inside the CV on the sidewall (See Figure 2-4). A larger RuBee Uber tag was also tested (See Figure 3-8). The Uber tag has greater power than the large asset tag and also benefits from separate transmit and receive antennas. With the Uber tag installed on the outside CV lid a range of roughly 4 feet was achieved with the drum lid flange bolts torqued to $45 \mathrm{ft}-1 \mathrm{bs}$. A handheld V-Rod model reader was also successful in communicating with the tags placed inside the packing.

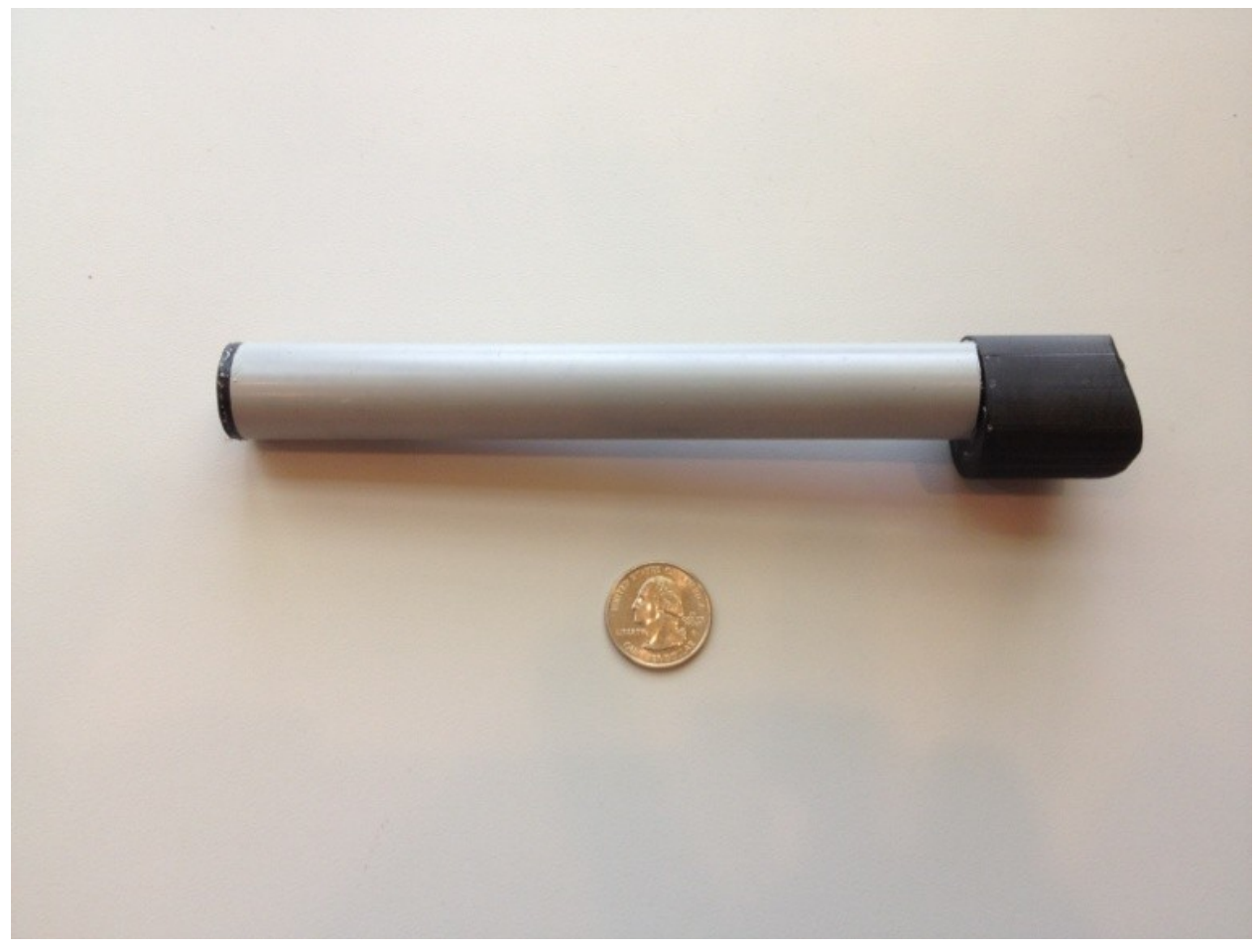

Figure 3-8. Visible Assets Uber Tag 


\subsection{Discussion of Results}

This testing demonstrated the feasibility of using RuBee magnetic field coupled tags and readers as a means of extracting sensor data from the interior of a 9977. It is important to stress that these results were obtained without any optimization of the tags and antennas for the application. The Ranger antenna used to read the tags for these tests is only used as a reference standard that enables designers to predict expected results with an antenna configuration more suited for the application. Combinations of larger ladder or loop style antennas mounted beneath, overhead or on the sides of stacked packages can be used to achieve the desired coverage in storage bays or transport vehicle cargo areas.

The RuBee tag operating frequency can be detuned when it is placed in contact with or in proximity of metal. It was observed during these tests that the tag operating frequency was detuned from $131 \mathrm{kHz}$ to $145 \mathrm{kHz}$ by placing it against the metal lid of the $\mathrm{CV}$. This detuning can be corrected for a known mounting configuration on metal by adjusting an internal tag capacitor to tune the tag to the desired operating frequency. Tuning will significantly enhance performance by closely aligning the tag and reader operating frequencies for maximum sensitivity.

\subsection{Conclusion and Recommendations:}

The results of this proof-of-concept testing show that RuBee magnetic field coupled tags and readers can be used to provide a sensor communication link from within a drum-style DOE Type B packaging. While this testing was performed specifically using a Model 9977, it is reasonable to conclude that similar results would be obtained with similar packagings, such as Models 9975 and 9978. The relatively small footprint and low power consumption of the RuBee tag make it an attractive candidate for interior sensor communications. It is anticipated that the battery life for a RuBee tag suitable for this application could be as long as 25 years due to the low operating frequency. Longer battery life may be achieved with additional power management measures and testing of higher quality battery options as they become available. RuBee's ability to work well when in contact with metal, the inherent security benefits of the signal propagation characteristics, and previous testing and vetting of RuBee technology for use in the Pantex Advanced Inventory and Materials Management pilot study are also major advantages for this technology. While the RuBee tags must be read at near-field distances in proximity to the material packages, a secure wireless or wired backhaul communications link could be used to pass tag sensor information to a local database access point either in a storage bay or transport vehicle application.

With the very promising results demonstrated in this proof-of-concept testing, the next steps to progress the application of this technology is to enhance the system tag performance by tuning and refining the antenna design and also pursue the integration of several applicable tag sensors. Additional testing would be performed to investigate the performance of suitable ladder and loop style reader antennas that could be used in storage and transportation applications. This effort will also explore a means of integration with the ARG-US RFID system. SRNL recommends and requests DOE PCP authorization to perform the following scope:

- Enhance tag performance with tuning and antenna optimization.

- Integrate several applicable tag sensors.

- Perform testing to determine a suitable reader antenna design for storage and transportation applications.

- Explore a means of integration with the ARG-US RFID system.

- Repeat the proof-of-concept test with the Model ES-3100 packaging to evaluate packaging using lightweight concrete (i.e., Kaolite) for thermal insulation. 